\title{
Metodologia de esporulação para fungos da família Botryosphaeriaceae
}

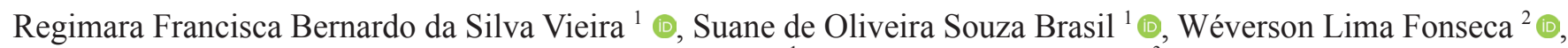 \\ Wallysson Nascimento Lima ${ }^{1} \mathbb{0}$, José Emilson Cardoso ${ }^{3}$ (우
}

${ }^{1}$ Departamento de Fitotecnia, Universidade Federal do Ceará, Avenida Humberto Monte - Pici, CEP: 60355636 - Fortaleza, CE, Brasil; ${ }^{2}$ Universidade Federal do Piauí, BR 135, Km 3 - Planalto Horizonte, CEP: 64900000 - Bom Jesus, PI, Brasil. ${ }^{3}$ Embrapa Agroindústria Tropical, Rua: Dra. Sara Mesquita, 2270 - Planalto Pici, CEP: 60511110 - Fortaleza, CE, Brasil

Autor para correspondência: Regimara Francisca Bernardo da Silva Vieira (bernardoregimara@gmail.com)

Data de chegada: 03/12/2019. Aceito para publicação em: 31/03/2020.

$10.1590 / 0100-5405 / 231724$

\section{RESUMO}

Vieira, R.F.B.S.; Brasil, S.O.S.; Fonseca,W.L.; Lima, W.N.; Cardoso, J.E. Metodologia de esporulação para fungos da família Botryosphaeriaceae. Summa Phytopathologica, v.47, n.1, p.62-64, 2021.

Os fungos pertencentes à família Botryosphaeriaceae são potenciais fitopatógenos e por apresentarem hábito cosmopolita, parasítico, endófitico e uma grande diversidade genética, morfológica e ecológica têm uma considerável importância nos estudos de doenças de plantas. A dificuldade para esporulação e os longos períodos de tal etapa no ciclo reprodutivo dos fungos desta familia são as principais limitações para a manipulação dos mesmos in vitro. Diante disto, este trabalho objetivou testar frutos de ata (Annona squamosa) como meio de cultura alternativo, afim de obter tempos de esporulação inferiores aos já descritos na literatura. Por fim, a utilização dos frutos de ata como meio de cultura demonstrou-se eficiente na esporulação dos isolados testados. Alem disso, dois dos isolados avaliados so foram capazes de esporular nos frutos de ata.

Palavras-chave: Annona squamosa, diversidade ecológica, meio de cultura.

\section{ABSTRACT}

Vieira, R.F.B.S.; Brasil, S.O.S.; Fonseca,W.L.; Lima, W.N.; Cardoso, J.E. Sporulation methodology for fungi of the Botryosphaeriaceae family. Summa Phytopathologica, v.47, n.1, p.62-64, 2021.

Fungi belonging to the Botryosphaeriaceae family are potential phytopathogens of considerable importance in plant disease studies due to their cosmopolitan, parasitic and endophytic habit, and great genetic, morphological and ecological diversity. The difficulty with sporulation and the long periods for such step in the reproductive cycle are the major limitations of handling these fungi in vitro. Thus, the present study aimed to test sugar apple fruits (Annona squamosa) as an alternative culture medium to obtain sporulation periods shorter than those described in the literature. Finally, the use of sugar apple fruits as a culture medium proved to be efficient for sporulation of the tested isolates. In addition, two of the evaluated isolates were only capable of sporulating in sugar apple fruits .

Keywords: Annona squamosa, ecological diversity, culture medium.

Os fungos que compõem a família Botryosphaeriaceae (filo Ascomycota e ordem Botryosphaeriales) estão comumente associados a doenças de plantas lenhosas sendo considerados de hábito cosmopolita tanto para o substrato onde são encontrados, quanto para região territorial onde se estabelecem $(1,2)$. São considerados extremamente agressivos sobre a grande maioria dos hospedeiros, podendo assim, serem classificados como ameaça potencial para agricultura (3). Em geral, estes fungos são caracterizados por possuírem hábitos parasíticos, saprofíticos e endofíticos, além disso, apresentam grande diversidade ecológica, morfológica e genética (4). Atualmente este grupo de fungos apresentam uma grande importância econômica devido a sua capacidade de infectar uma ampla gama de hospedeiros, além dos seus hábitos ecológicos em diferentes ecossistemas (4). Os fungos desta família apresentam características bastante variadas em meios de cultura artificiais, apresentado diferenças na coloração das colônias, velocidade de crescimento micelial e esporulação dependendo do gênero e da espécie do fungo (6). O objetivo deste trabalho foi estudar a influência dos meios BCA, BCA + acícula e frutos de ata em fotoperíodos de $12 \mathrm{~h}$ na esporulação de fungos da família Botryosphaeriaceae obtidos de diferentes hospedeiros.
Foram selecionados oito isolados pertencentes à família Botryosphaeriacea da coleção de fungos do Laboratório de Fitopatologia da unidade da Embrapa Agroindústria Tropical (CNPAT) provenientes de diferentes plantas hospedeiras, tais como cacaueiro, cajueiro, cirigueleira, mangueira e neem, coletados de diferentes locais do Nordeste brasileiro. Sendo que o isolado do cacaueiro foi relatado causando sintoma de morte descendente, os isolados do cajueiro ocasionando sintomas de morte descendente, podridão preta da haste e resinose, o isolado da cirigueleira associado a morte descendente, $\mathrm{o}$ isolado de mangueira causando morte descendente e o isolado de neem causando seca do colo. Estes isolados foram escolhidos por apresentarem dificuldade de esporulação em meios de cultura convencionais, testados anteriormente. Os 8 isolados foram recuperados da preservação do tipo Castellani e colocados para crescer em meio de cultura batata-dextrose-ágar (BDA) a $25^{\circ} \mathrm{C} \pm 2{ }^{\circ} \mathrm{C}$. Em seguida, após 3 dias, discos de micélio de $7 \mathrm{~mm}$ de diâmetro proveniente da borda da colônia, foram transferidos e colocados no centro de novas placas de Petri contendo batata-cenoura-ágar (BCA), BCA + acículas e para frutos verdes de ata, cada isolado com três repetições. Os frutos de ata passaram por um processo de esterilização em autoclave com pressão 


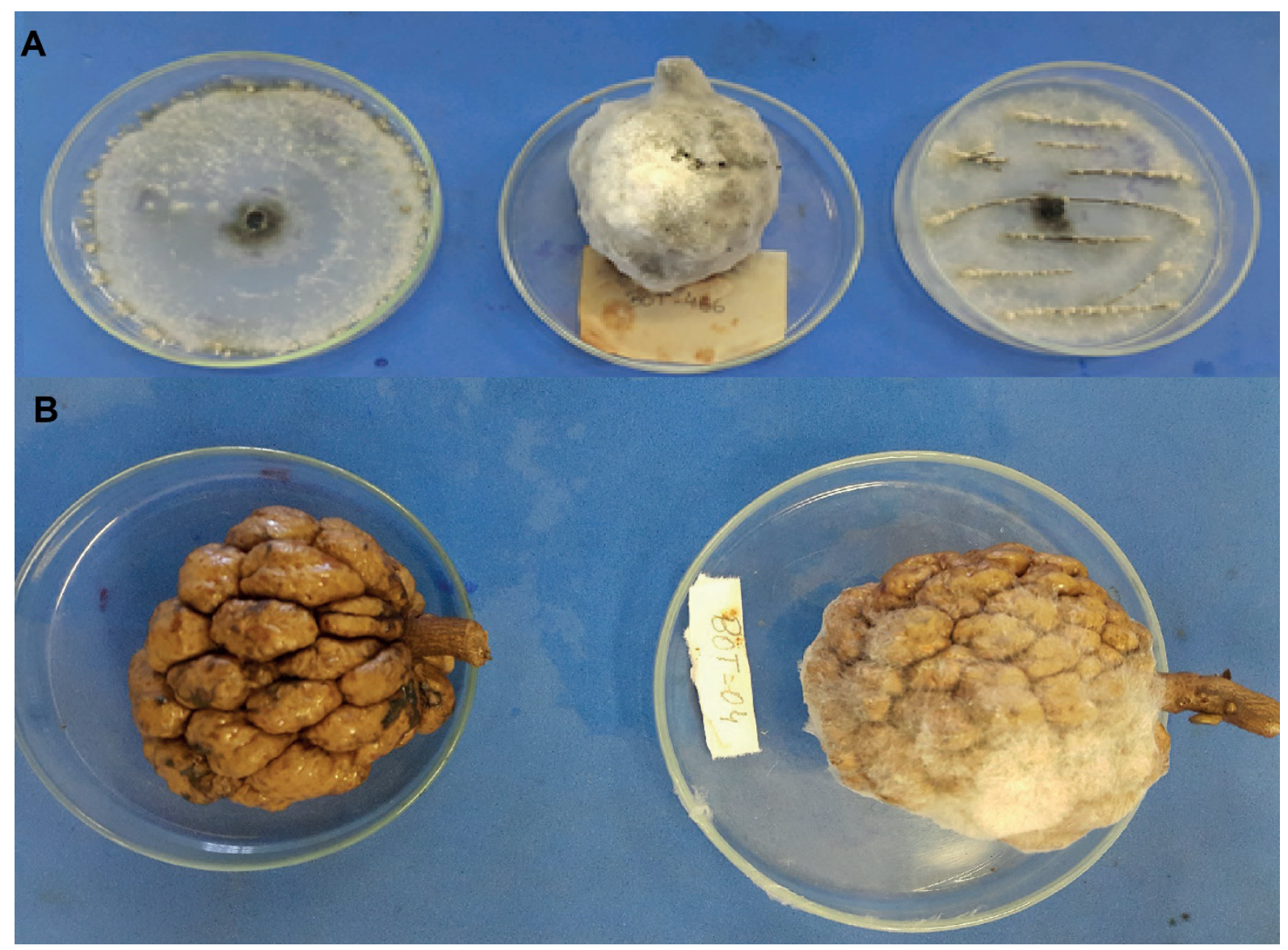

Figura 1. Em A, o isolado BOT 466 nos três meios de cultura utilizados. Em B, o isolado BOT 04 com a testemunha ao seu lado esquerdo.

de $1 \mathrm{~atm}$, durante 15 minutos. As placas de Petri contendo BCA e $\mathrm{BCA}+$ acícula, foram incubados a $28{ }^{\circ} \mathrm{C} \pm 2{ }^{\circ} \mathrm{C}$, com fotoperíodo alternado de $12 / 12 \mathrm{~h}$, onde foram avaliados o crescimento micelial e a presença de picnídios. Os frutos foram mantidos em câmara úmida e temperatura ambiente durante todo o experimento, sendo os mesmo armazenados em bandeja de plástico, que foram esterilizadas com álcool 70\%, e em seguida coberto com um plástico transparente e adicionados algodão umedecido com água destilada e esterilizada, nas laterais da bandeja sendo substituído a cada dois dias, com fotoperíodo alternado de $12 / 12 \mathrm{~h}$. A avaliação de crescimento micelial dos isolados foi realizada diariamente (longitudinal e latitudinal) com o auxílio de um paquímetro (placas Petri) e uma fita métrica (frutos de ata). Já a avaliações da presença de picnídios e esporulação foram realizadas com 15 e 30 dias, após a instalação do experimento. $\mathrm{O}$ teste foi conduzido em delineamento inteiramente casualizado com 3 repetições, sendo cada repetição uma placa de Petri ou um fruto. Os dados foram submetidos à análise de variância pelo teste $\mathrm{F}(\mathrm{p}<0,05)$ e as médias agrupadas pelo teste de Scott-Knott a $5 \%$ de probabilidade através do software estatístico R, versão 3. 5. 1 .

Os resultados deste experimento estão apresentados na Tabela 1. Dentre os isolados testados, quando se utilizou os frutos da ata para a esporulação, os isolados do Cacau, BOT 04, BOT 456, BOT 466 e BOT 457 formaram picnídios muito mais rápido com 15 dias, quando comparados aos outros meios testados, no qual não apresentaram a presença de picnídios e quando apresentaram não tinham esporos (conídios). Esta metodologia com a utilização frutos de ata para induzir a esporulação de fungos da família Botryosphaeriaceae foi testada pela primeira vez neste trabalho. Até então, os estimulantes mais utilizados e descritos na literatura para induzir a esporulação de fungos desta família eram através do incremento de acículas no meio de cultura, submetidas a luz negra ou o uso meio de culturas variados $(7,5)$. Inúmeras suposições podem justificar a ocorrência desses comportamentos distintos do material analisado e todas elas apontam para a composição química, seja dos frutos, seja dos fungos $(8,9)$. Neste experimento, também foi possível perceber que alguns isolados foram capazes de formar o corpo de frutificação (picnídios), mas não formaram conídios até o período final de avaliação (Tabela 1). Vale ressaltar que os isolados BOT 04 e BOT 456, não conseguiram esporular em meio BCA e BCA + acículas, sendo capazes de formar picnídios e conídios apenas no meio de cultura alternativo (frutos de ata).

Alem disso, foi possível verificar que a maior velocidade de crescimento micelial foi observada nos meios BCA e BCA + acícula, com crescimento diferenciado entre os isolados avaliados. Conforme a análise, o isolado BOT 04 cresceu de forma rápida, porém não formou picnídio e não esporulou. De modo abrangente, utilizando frutos de ata como meio de cultura, os isolados tiveram as menores velocidades de crescimento, no entanto, a formação de picnídio e esporulação foi mais rápida, com exceção do isolado BOT 220.

Por fim, de acordo com os resultados obtidos conclui-se que a utilização do meio de cultura alternativo utilizando frutos de ata foi o que apresentou maior rapidez na esporulação dos isolados testados. Adicionalmente, os isolados BOT 04 e BOT 456 só foram capazes de esporular em frutos de ata. 
Tabela 1. Índice de velocidade de crescimento micelial, formação de picnídios e esporulação de isolados de Botryosphaereaceae em três substratos.

\begin{tabular}{|c|c|c|c|c|c|c|}
\hline \multirow{2}{*}{ Isolados } & \multicolumn{3}{|c|}{ Índice de velocidade de crescimento } & \multicolumn{3}{|c|}{ Presença de picnídios / Esporulação (dias) } \\
\hline & BCA & BCA+ACÍCULA & ATA & BCA & BCA+ACÍCULA & ATA \\
\hline Cacau & $4,88 \mathrm{cA}$ & $4,97 \mathrm{bA}$ & $3,55 \mathrm{bB}$ & $+/ 29$ & $+/ 19$ & $+/ 11$ \\
\hline BOT 220 & $3,93 \mathrm{dA}$ & $3,95 \mathrm{dA}$ & $3,19 \mathrm{cB}$ & $+/ 19$ & $+/ 19$ & $+/ 29$ \\
\hline BOT 344 & $5,54 \mathrm{aA}$ & 5,45 aA & $3,36 \mathrm{cB}$ & $+/-$ & $+/ 19$ & $+/ 19$ \\
\hline BOT 457 & $5,18 \mathrm{bB}$ & $5,24 \mathrm{aB}$ & $5,68 \mathrm{aA}$ & $+/ 29$ & $+/ 19$ & $+/ 11$ \\
\hline BOT 464 & $4,91 \mathrm{cB}$ & $5,28 \mathrm{aA}$ & $3,65 \mathrm{bC}$ & $+/-$ & $+/-$ & $+/-$ \\
\hline BOT 466 & $4,68 \mathrm{cA}$ & $4,29 \mathrm{cB}$ & $3,38 \mathrm{cC}$ & $+/ 19$ & $+/ 19$ & $+/ 11$ \\
\hline $\operatorname{Pr}>F^{1}$ & & 0,001 & & & - & \\
\hline
\end{tabular}

(1) Probabilidade maior que F para a interação: Médias seguidas de mesma letra maiúscula na linha e minúscula na coluna não diferem significativamente pelo Teste de Scott-Knott a 5\% de probabilidade. + e -, presença ou ausência de picnídios e esporulação.

\section{AGRADECIMENTOS}

Ao Conselho Nacional do Desenvolvimento Científico e Tecnológico e a Fundação Cearense de Apoio ao Desenvolvimento Científico e Tecnológico pelas bolsas de estudos dos discentes.

\section{REFERÊNCIAS}

1. Alexandre, E. R.; DE Oliveira, J.; DE Oliveira, Sônia M. A.; DA Silva, Josenilda M.. Radiação gama sobre agentes fitopatogênicos da manga da cultivar Tommy Atkins. Revista Brasileira de Ciências Agrárias, v. 7, n. 1, 2012.

2. Cardoso, J. E.; Viana, F. M. P.; Martins, M. V. V. Doenças causadas por fungos da família Botryosphaeriaceae em cajueiro. Embrapa Agroindústria Tropical-Circular Técnica (INFOTECA-E), 2018.

3. Gonçalves F.J.; Freire F.D.; Lima J.S., Melo J.G.; Câmara M.P.. Patogenicidade de espécies de Botryosphaeriaceae endofíticas de plantas da Caatinga do estado do Ceará em manga e umbu-cajá. Summa Phytopathologica, v. 42, n. 1 , p. $43-52,2016$.

4. Halfeld-vieira, B. de A.; Nechet, K. de L.; DE Souza, G. R. Influência de Meios de Cultura e Regimes de Luz na Esporulação e Crescimento Micelial de Lasiodiplodia theobromae. Embrapa Roraima-Boletim de Pesquisa e Desenvolvimento (INFOTECA-E), 2007.
5. LIMA, J. S.; Cardoso, J. E.; Moreira R. C.; Alves, E. S.; Lima, F. A.; Anjos, R. M.; Viana, F. M. P... Crescimento micelial e esporulação de isolados de Lasiodiplodia theobromae em substratos vegetais. In: Embrapa Agroindústria Tropical-Artigo em anais de congresso (ALICE). In: CONGRESSO BRASILEIRO DE FRUTICULTURA, 21., 2010, Natal. Anais... Natal: Sociedade Brasileira de Fruticultura, 2010., 2010.

6. Nerendra, N; Almeida J. Das N.; Galvao, M. De S.; Madruga, M. S.; Brito, E. S.. Compostos voláteis dos frutos de maracujá (Passiflora edulis forma Flavicarpa) e de cajá (Spondias mombin L.) obtidos pela técnica de headspace dinâmico. Ciência e Tecnologia de alimentos, v. 24, n. 2, p. 212-216, 2004

7. Oliveira, F. C.; Barbosa, F. G.; Mafezoli, J.; Oliveira, M. Da C. F. De O.; Goncalves, F. J. T.; Freire, F. C. O.. PERFIL DOS COMPONENTES VOLÁTEIS PRODUZIDOS PELO FUNGO FITOPATÓGENO Albonectria rigidiuscula EM DIFERENTES CONDIÇÕES DE CULTIVO. Química Nova, v. 40, n. 8, p. 890-894, 2018.

8. Phillips, A. J. L.; Alves, A.; Abdollahzadeh, J.; Slippers, B.; Wingfield, M. J.; Groenewald, J.Z.; Crous, P. W.; . The Botryosphaeriaceae: genera and species known from culture. Studies in mycology, v. 76, p. 51-167, 2013.

9. Punithalingam, E. Plant diseases attributed to Botryodiplodia theobromae Pat (Bibliotheca Mycologica). J Cramer, Vaduz Berlin, 1980. 